\title{
DEMANDA POR UM CURSO DE LICENCIATURA EM LÍNGUA INDÍGENA NA UFRR
}

\author{
DEMAND FOR AN INDIGENOUS LANGUAGE GRADUATION COURSE AT UFRR
}

\author{
Paulo Fernando de Lucena Borges Ferreira ${ }^{1}$
}

\begin{abstract}
RESUMO: Trata-se de um Artigo com a finalidade de compor publicação no Periódico da Universidade do Acre UFAC, Muiraquitã. Tem por finalidade compreender a necessidade da criação de Cursos Superiores de Línguas Indígenas. Para cumprir esse propósito foram selecionados, em perfil bibliográfico qualiquantitativo de pesquisa (misto), autores como Bobbio (1992), Alvim (1995), UFRR (2001), Santos (2004), Canclini (2004), Baniwa (2008), Fernandes, Carvalho e Repetto (2009), Bernardi (2011), Baptaglin (2017), o que possibilitou maior compreensão e contextualização da presente temática. Dentro do modelo quantitativo a pesquisa indica uma demanda real e atual dentro da UFRR: a necessidade de um curso de formação superior em Língua Indígena. Ao passo que novos desafios vão surgindo dentro do fazer e da vivência acadêmica, se faz necessário novas dinâmicas administrativas e de políticas formativas que atendam e garantam direitos de diferentes grupos, inclusive dos indígenas de Roraima e do país, bem como os de todos aqueles que tenham interesse em aprender (de maneira certificada) um curso destas culturas históricas/ atuais diversificadamente constituídas. Dos dados coletados, se pôde perceber que um Curso de Formação Superior em Língua Indígena pelo Insikiran, serviria para superação de obstáculos para a obtenção de uma certificação acadêmica de interessados em aprender uma das línguas indígenas de Roraima, como a exemplo de problemas com deslocamento, moradia e custeio de estudos.
\end{abstract}

Palavras-chave: Formação Superior. Línguas Indígenas. Multiculturalismo. Universidade Federal de Roraima.

ABSTRACT: It is an article for the purpose of composing a publication in the University of Acre Journal - UFAC, Muiraquitã. Its purpose is to understand the need for the creation of Higher Courses of Indigenous Languages. In order to fulfill this purpose, authors such as Bobbio (1992), Alvim (1995), UFRR (2001), Santos (2004), Canclini (2004), Baniwa (2008), Fernandes, Carvalho and Repetto (2009), Bernardi (2011), Baptaglin (2017), which made possible a better understanding and contextualization of the present theme. Within the quantitative model the research indicates a real and current demand within the UFRR: the need for a higher education course in Indigenous Language. While new challenges are emerging within the framework of academic achievement and living, new administrative and training policy dynamics are needed to meet and guarantee the rights of different groups, including the indigenous people of Roraima and the country, as well as those of all those who have an interest in learning (in a certified manner) a course of these diverse / historically constituted cultures. From the collected data, it was possible to realize that a Course of Higher Education in Indigenous Language by Insikiran, would serve to overcome obstacles to obtain an academic certification of interested in learning one of the indigenous languages of Roraima, such as problems with displacement, housing and education costs.

Keywords: Higher Education. Indigenous Languages. Multiculturalism. Federal University of Roraima.

1 Pedagogo, Bacharel em Direito e professor licenciado em Português-Espanhol; Pós-graduado em Atendimento Educacional Especializado - AEE e Educação Inclusiva. Mestre em Letras pela Universidade Federal de Roraima - UFRR. 


\section{INTRODUÇÃo}

Este artigo tem por interesse e objetivo compreender a necessidade da criação de Cursos Superiores de Línguas Indígenas. Esta proposta surge no sentido de pensar possibilidades de disponibilizar Cursos de Formação Superior de Línguas Indígenas, assumindo assim um novo posicionamento da formação acadêmica e exercício cidadão de emancipação dos indivíduos que compõem esses núcleos sociais que são histórica e culturalmente diversificados.

Em respeito à diversidade de formação étnica de Roraima, mais especificamente relativa aos povos indígenas, a Universidade Federal de Roraima (UFRR) criou no ano de 2001, por meio Resolução 015/2001², o Núcleo Insikiran que veio contribuir para a formação acadêmica e o exercício de uma cidadania intercultural que englobe direitos e liberdades já reconhecidos em demandas internacionais como o direito à vida, a livre determinação dos povos, à justiça, igualdade de tratamento e tutela diante da lei, liberdade de expressão, informação, direitos relativos às minorias étnicas, religiosas e linguísticas bem como a ao exercício e reconhecimento de sua própria cultura. Atualmente o Instituto Insikiran possui três cursos de graduação, a saber: Licenciatura Intercultural, criado no ano de 2001; Curso de Bacharelado em Gestão Territorial Indígena, em 2009 e o Curso de Bacharelado em Gestão de Saúde Coletiva Indígena, criado no ano de 2012. Todos estes cursos são ministrados por meio de aulas presenciais na capital de Roraima, Boa Vista. Deve ser considerado que a maioria destes acadêmicos é de origem de comunidades indígenas nas mais diferentes partes do Estado, havendo necessidade de que empreguem investimento financeiro com transporte ou ainda habitação, para cursarem suas graduações.

Atender essa demanda superior de formação acadêmica aos povos indígenas é reconhecer que estes povos possuem características socioculturais específicas, não podendo ser generalizadas pela individualidade, mas abrangendo de maneira ampla, seus direitos coletivos, surgindo nesse momento à possibilidade de pensar Estados Interculturais, onde se privilegie e se valore contextos de diversidades culturais e elementos diferenciados de construção social (REPETTO, 2008).

Visando adentrar em discussões teóricas que possibilitem melhor compreensão deste cenário buscamos trabalhar com estudos de Baniwa (2010), Bobbio (1992), Canclini (2004), Cavalcanti e César (2007), Fernandes (2008), Freitas (2003) e Meliá (1999), Maher (2007), McLAREN (2000), possibilitando uma melhor discussão sobre a ótica de estudo.

Para sistematização dos dados buscamos trazer, além das proposições teóricas acerca da Educação à distância, da Formação Superior Indígena e da Língua indígena, uma pesquisa de campo com narrativas de professores do Insikiran/UFRR que vem trabalhando com as Línguas indígenas no sentido de proporcionar maior compreensão do cenário em estudo.

Compreender as demandas de Formação Superior em Língua Indígena em Roraima amplia o olhar para as possibilidades que podem ser evidenciadas haja vista que não existem ainda graduações com este teor, tendo somente sido disponibilizado cursos de extensão acadêmica por professores falantes de línguas indígenas locais. Todavia, essa investigação junto com as ações já realizadas no Insikiran pode possibilitar uma visão mais ampla sobre o direito de acesso à Formação Superior dos povos indígenas de Roraima dentro das suas realidades multiculturais. Ainda serve para despertar o interesse para que sejam feitos outros estudos que oportunizem discussões sobre este assunto.

\section{Políticas PÚblicas PaRa FORMaÇão SUPERIOR EM RoRAima}

Implantada no de $1989^{3}$, a Universidade Federal de Roraima, desde a sua fundação, tem oportunizado formação acadêmica de excelência e de referência no norte do Brasil. Dentro de

2 Universidade Federal de Roraima.Instituto de Formação Superior Indígena Insikiran - “Apresentação". Disponível em: < http:// ufr.br/insikiran/index.php?option=com_content\&view=article\&id=60\&Ite>. Acesso em 29 de mar. de 2018

3 Universidade Federal de Roraima. Histórico Disponível em: <http://ufrr.br/a-ufrr/historico>. Acesso em 29 de mar. de 2018 
suas estruturas, atividades acadêmicas e fluxos de gestão administrativa têm privilegiado conteúdos firmados diretamente na pluralidade étnica, diversidade de formação história dos povos, multiculturalismo, alto desempenho profissional e elevado padrão de capacitação técnica.

A política nacional com viés de formação superior por meio de diferenciados conteúdos em território nacional é baseada no Referencial Curricular Nacional para as Escolas Indígenas (RCNEI). São diretrizes e orientações fundamentais para o trabalho com diferentes áreas do saber com propósito de formação nas escolas indígenas inseridas no Ensino Fundamental. Conforme prevê o Ministério da Educação, o RCNEI tem por finalidade oferecer bases orientadoras para o desenvolvimento de programas de educação escolar no contexto indígena, atendendo aos seus próprios interesses e peculiaridades. No entanto, este contexto, não pode, ou não deveria afastar-se de princípios como pluralidade cultural e equivalência de tratamento para os cidadãos como um todo. Tal posicionamento também deve ser fundamento para a elaboração de material didático para a formação de professores indígenas (BRASIL, 1998).

Paladino (2012) constata hoje no Brasil a existência de 26 cursos de Licenciaturas Interculturais, funcionando junto às Universidades Públicas, todos financiados pelo Ministério da Educação, exclusivamente para a formação de professores, mas isso pode ser ampliado, contemplando até mesmo a Educação a Distância. Surgem, aos poucos, bacharelados específicos, como por exemplo, em Gestão Territorial Indígena (Instituto Insikiran- UFRR), bem como Faculdades Interculturais. Outra forma que possibilita a presença de estudantes no ensino superior é propiciada por políticas de cotas, que se materializa em fomentar o ingresso por meio de reserva de vagas, bem como bônus que consiste em acréscimo de pontos nos processos seletivos e vagas suplementares em cursos regulares e convencionais.

Nesse movimento de descoberta se reconhece a própria cultura como algo que está posto dentro de um processo de modificação construtiva de um processo histórico, aumentando a verificação que os "direitos individuais e coletivos diversificados" são direitos históricos, cuja gênese está fecundada nas experiências vividas por um núcleo social através dos tempos (BOBBIO, 1992, p. 18).

Pode-se compreender que há um grande interesse dos povos indígenas pelo ensino superior, podendo ela servir como: "[...] ferramenta para promover suas próprias propostas de desenvolvimento, por meio do fortalecimento de seus conhecimentos originários, de suas instituições e do incremento de suas capacidades de negociação, pressão e intervenção dentro e fora de suas comunidades". A universidade pode contribuir e construir ou reforçar a autoestima coletiva dos povos ameríndios, reforçando assim as suas identidades étnico-culturais (BANIWA, 2010, p.8).

Nas palavras de Fernandes, Carvalho e Repetto (2008), há uma grande necessidade de acesso aos professores indígenas à qualificação superior de suas formações acadêmicas:

É importante ressaltar a necessidade em formas específicas de ingresso para indígenas e, sobretudo, de estratégias para garantir a permanência dos mesmos no ensino superior [...] Dessa forma, pode-se afirmar que a atuação do Núcleo Insikiran foi um avanço sem precedente. Prova disso é que em 2007 ingressaram 71 novos estudantes indígenas somente por meio de Processo de Seleção Específica na UFRR, sem contar os que entraram por processo regular (5 alunos), [...] Há que se garantir a criação de políticas permanentes nessas instituições [...] Somente assim os estudantes poderão atender as suas comunidades e contribuir com a melhoria da qualidade de vida das mesmas (FERNANDES; CARVALHO; REPETTO, 2008, p. 42). 
Compreender as implicações necessárias às especificidades dos povos e suas culturas e trazer ao debate a desconstrução de um paradigma homogeneizante que cria uma falácia que todos seriam iguais. Seria um equívoco não levar em consideração que há diferentes características cognitivas e culturais estando desigualmente distribuídas (CANCLINI, 2004).

Nossa individualidade não teria existência se o outro não a criasse. A distância para compreender inicia “o processo dialógico". Conhecer é reconhecer a presença do outro: a compreensão sempre é, em certa medida, dialógica (BAKTHIN, 1992, p. 55).

O Parecer n. ${ }^{014}$ da Câmara da Educação Básica (CEB) do Conselho Nacional de Educação (CNE) (BRASIL, 1999, p.14) descreve que a formação do professor indígena deve se dar de acordo com a "sua própria escolarização". Esse parecer observa que a formação do professor indígena pressupõe o comprometimento com um currículo de formação diferenciada adequada às suas especificidades, formação multiculturalizada e processo histórico de desenvolvimento baseado em elementos de etnicidade. Essa formação deve, portanto, abranger, necessariamente:

\footnotetext{
- Capacitação para a elaboração de currículos e programas de ensino específicos para as "Escolas indígenas"; - Capacitação para produzir material didático-científico; - Capacitação para um ensino bilíngue, o que requer conhecimento em relação aos princípios de Metodologia de ensino de segundas línguas, seja a segunda língua em questão a língua portuguesa ou a língua indígena; - Capacitação sociolinguística para o entendimento dos processos históricos de perda da linguística, quando pertinente; - Capacitação linguística específica, vez que, de maneira geral, cabe a este profissional a tarefa de liderar o processo de estabelecimento de um sistema ortográfico de língua tradicional de sua comunidade;

- Capacitação para a condução de estudos de cunho linguístico e antropológico, uma vez que este profissional, enquanto necessariamente, autor e condutor dos processos de elaboração de materiais didáticos para as escolas indígenas, devem ser capazes de: a) realizar levantamentos de literatura indígena tradicional e atual; b) realizar levantamentos étnico-científicos; c) lidar com o acervo histórico do respectivo povo indígena; d) realizar o levantamento sócio-geográfico de sua comunidade (BRASIL, 1999, p.14).
}

Para que essas necessidades e formalizações, já fomentadas por entendimentos de estudiosos sociais, antropólogos, pedagogos e outros conhecedores de diversos e diferentes campos de conhecimento, se concretize com qualidade e com a devida aplicação social, enobreceria os direitos humanos e garantias constitucionais de preservação da cultura e o acesso à educação. Ainda deve ser levado em consideração, quanto a estes aspectos de multiculturalismo, que a valorização dessas compreensões e diversificações de conteúdos de formação, não poderiam ser comparadas com perspectivas de "temáticas indígenas" como tema de modismos, conceitos e paradigmas que mais afastam que integralizam essas sociedades.

Baniwa (2009) identifica que profissionais e intelectuais indígenas encontram resistências:

Hoje os acadêmicos e profissionais indígenas sofrem dupla exclusão ou discriminação. São percebidos como ameaças aos postos de lideranças indígenas e ameaças aos postos de assessorias e consultorias para questões indígenas entre os dirigentes e equipes técnicas das ONGs. Em função disso são excluídos dos processos de discussões, de espaços de tomadas de decisões e dos espaços de execução e ações e políticas. Quando a ameaça é mais eminente e real, a justificativa para garantir o trabalho e o salário dos assessores não-índios é a concorrência pela qualidade técnico-científico, além é claro do tempo de experiência, sabendo-se que os indígenas egressos das universidades ainda não dispõem desses requisitos e se não lhes forem dados oportunidades o que poderia ser com a legítima justificativa de domínio do notório saber, tão cedo não terão condições de concorrer de forma igualitária com os não-índios, uma vez que ainda levarão tempo para ter seus primeiros especialistas reconhecidos nacional ou internacionalmente, mestres e doutores (BANIWA, 2009, p. 8-9). 
Esses desafios voltam-se também para a necessidade de que estas formações ainda devem criar oportunidades de correlacionar conhecimentos diversificados com aquele, proporcionalmente ao conhecimento necessário ao contexto que irá ser aplicado, pois cada comunidade indígena, suas formações e suas afirmações, estão inevitavelmente construídas nas especificidades de suas identidades, como anteriormente já contemplado neste estudo:

Mesmo com um número significativo de profissionais indígenas habilitados, as oportunidades e os espaços estratégicos no âmbito interno do movimento indígena e no âmbito das políticas públicas continuam sendo ocupadas por profissionais não indígenas especialmente ligadas às $\mathrm{ONG}$ s indigenistas na maioria das vezes com apoio das próprias organizações indígenas. A justificativa é sempre que os indígenas não estão suficientemente preparados e qualificados para exercer tais tarefas, pois os cursos universitários não dão conta disso, o que pode ser verdade, mas que poderia ser complementado com cursos específicos, aliás, como fazem para suas equipes técnicas os não indígenas que também saem das universidades com as mesmas deficiências na formação (BANIWA, 2008).

O papel das Universidades nacionais e Centros Acadêmicos sejam eles públicos ou pertencentes às redes privadas é identificar e viabilizar o acesso de indígenas à educação superior assim como de outros grupos étnicos e sociais em condições desigualdade, precisando urgentemente que essas instituições possam ir além dos mecanismos comuns para disponibilização de vagas. As ações afirmativas são vantajosas, pois representam uma oportunidade que de outra forma os indígenas, por exemplo, não teriam acesso à formação superior.

\section{Demandas POR UMa FORMaÇão EM Língua Indígena EM RoRaima}

Ao iniciarmos a nossa análise, destacamos que os questionários da pesquisa foram entregues ao Insikiran/UFRR. Acompanhado do questionário entregamos os seguintes documentos: 1-Solicitação de Autorização Institucional para o Desenvolvimento de Pesquisa (Comitê de ética); 2. Termo de Consentimento e Livre Esclarecimento; 3. Cópia de Espelho do Protocolo de Pesquisa deste Projeto encaminhado à Plataforma Brasil; 4. Cópia do Presente Projeta de Pesquisa e, 5. Questionário.

Isto é uma realidade de um presente momento, geradora de uma demanda que há que ser considerada pra UFRR, visando proporcionar políticas acadêmicas que possam suprir esse novo momento par a viabilização de contextos formativos mais amplos e diversificados.

Relembrando um momento histórico anterior, Repetto; Carvalho e Fernandes (2009) realizaram uma investigação na década de que 90 , onde já indicavam algumas demandas referentes à necessidade de formação superior indígena. Após esse momento, já adentrando os anos 2000, o Programa E'ma Pia, mantido pelo Insikiran, se organizou no sentido de atuar em onze frentes de ação:

1) diagnóstico da presença e levantamento da demanda de indígenas de Roraima por educação superior;

2) curso pré-vestibular;

3) eventos técnicos científicos e cuturais;

4) cursos de extensão;

5) cursos de leitura e produção textual;

6) publicações;

7) reforma da casa do estudante e da cultura indígena;

8) centro de documentação e pesquisa em educação escolar indígena;

9) fundo de financiamento de projetos à pesquisa de estudantes indígenas da UFRR;

10) laboratório de informática e;

11) cursos de graduação (FERNANDES; CARVALHO; REPETTTO, 2009, p.10). 
No decorrer da criação dessa rede de formação Superior indígena na UFRR, o Insikiram passou a efetivar de maneira mais plena os moldes de sua estrutura acadêmica lançando seus cursos de graduação: Licenciatura Intercultural criado no ano de 2001, Curso de Bacharelado em Gestão Territorial em 2009 e o Curso de Bacharelado em Gestão de Saúde Indígena, criado no ano de 2012. Todos eles têm sido ministrados de forma presencial. Sendo que, mesmo no início de suas atividades Fernandes; Carvalho; Repetto (2009), conforme informações presentes em entrevista com alunos que não residiam em Boa Vista, destacaram como dificuldades para esses acadêmicos virem cursar uma graduação na sede do Instituto Insikiran, o fato de trabalharem nas comunidades, falta de transporte ou carona e local para permanência.

Deve ser considerado que Roraima é subdividido em 15 municípios e tem um território com $224300,506 \mathrm{~km}^{2}$ de área, sendo que aproximadamente $104.018 \mathrm{~km}^{2}$ são áreas indígenas, representando quase metade $(46,37 \%)$ do território desta unidade da federação, onde habitam mais de diferentes povos localizados em diferentes comunidades, em diversas extensões de terra. A maioria dos membros dessas comunidades não reside na capital do Estado, mas no interior deste (FRANK; CIRINO, 2010).

Foi nesse intuito que surgiu o Instituto de Formação Superior Indígena Insikiran na UFRR, com o interesse e finalidade de compreender a realidade dos diferentes povos indígenas de Roraima e viabilizar diferentes estratégias e políticas públicas que se adequem a necessidade desses acadêmicos. Cohen, Fonseca e Carvalho (2016) ressaltam o seguinte:

O Instituto Insikiran é uma Unidade Acadêmica da UFRR que se caracteriza pela atuação política-pedagógica de formação para os povos indígenas do estado de Roraima no campo da educação específica, diferenciada e intercultural.

A instituição promove ensino, pesquisa e extensão oferecendo atividades de formação à população indígena em geral, visando divulgar os princípios de interculturalidade e a realidade dos povos indígenas: a) Promovendo a valorização dos saberes indígenas no processo de construção de conhecimentos nos cursos de graduação e preparação para a pós-graduação no âmbito do Instituto por meio do diálogo com os povos indígenas e sociedade em geral; b) Produzindo conhecimentos para subsidiar a formulação de políticas públicas em atenção aos povos indígenas e a sociedade em geral; c) Articulando as teorias e práticas na formação e atuação dos alunos indígenas; d) Dialogando com os povos indígenas na construção da educação intercultural; e) Assessorando a elaboração e revisão de propostas político-pedagógicas e curriculares das escolas indígenas, bem como apoiar a formação profissional técnica no âmbito da educação básica nas escolas indígenas por meio de projetos específicos (COHEN; FONSECA; CARVALHO, 2016, p.272-273).

Segundo Cohen, Fonseca e Carvalho (2016) o Insikiran tem suma importância para a busca de respostas políticas e sociais na administração relativa à formação superior na UFRR abrangendo reinvindicações indígenas em Roraima, tonando-se:

[...] um centro de discussões sobre as problemáticas indígenas e espera-se também que se torne um centro de alto nível para formação de professores e estudantes indígenas e busque gerar condições para que os mesmos sujeitos do processo possam elaborar programas de estudos atualizados que levem as alternativas para os desafios que as comunidades enfrentam na atualidade (COHEN; FONSECA; CARVALHO, 2016, p.273).

Vale esclarecer conforme Baptaglin (2017), que a formação superior das instituições acadêmicas deve viabilizar mediações que se amoldem às realidades presentes nas diversidades culturais das sociedades atuais. Essas novas necessidades devem atuar de modo a não só promover um diálogo amplo de contato, mas personificar políticas públicas que se apresentem como soluções para essas novas exigências formativas. 
À medida que os dados forem sendo apresentados, ficará mais claro o que tem sinalizado esses contextos da pesquisa, há tanto viabilidade como necessidade de uma Rede de Formação Superior em Língua Indígena, que poderia ser ofertada pela UFRR.

\section{Cenários Construtores}

Ao tratarmos dos Cenários Construtores, estamos trazendo os contextos que se apresentam como reveladores da importância da disponibilidade um Curso de Formação Superior em uma das línguas indígenas de Roraima para os alunos da UFRR e indicadores da existência de uma estrutura que possibilitaria a disponibilização deste curso.

Referente à Viabilidade da estruturação de um Curso de Formação superior em uma das línguas indígenas de Roraima, Ramos (2018) pontou dois motivos: "1. A valorização das Linguas Indígenas de Roraima e, 2. A perpetuação das Linguas Nativas de Roraima”. Braggio (2001) destaca bem a necessidade de disponibilidade de cursos de aprendizado e prática de línguas indígenas brasileiras ao enfatizar que tal atitude pode proporcionar a continuidade desse traço cultural destes povos que compões a matriz étnica de nosso país. Compreender essas demandas também é papel das instituições de formação superior de nosso país.

Compreender a viabilidade de um curso de Formação Superior indígena em uma das línguas indígenas de Roraima está diretamente amoldado a este novo paradigma que desconstrói limitações de acesso à formação superior e reestrutura aquilo que agora apresenta-se como um novo olhar sobre a profissionalização daqueles que quiserem compreender mais sobre uma das línguas dos povos indígenas de Roraima.

Sobre isto, Oliveira (2003, p.39) informa que a Declaração dos Direitos Linguísticos, mais precisamente em seus artigos 46 estabelece que "toda comunidade linguística tem direito à preservação de seu patrimônio linguístico e cultural".

De igual modo, Santos (1975) esclarece que as instituições de ensino superior devem ofertar possibilidade de formação acadêmica voltada as necessidades de povos com constituição étnica, histórica e cultural altamente diversificadas, como a exemplo dos povos indígenas de Roraima. Isso só vem a enobrecer os direitos diversificados das minorias.

Maher (2007), também tece comentários sobre a formação superior de professores que tratem sobre Língua indígena, destaca que não há com se considerar diversidades culturais sem abranger possibilidades, aos povos indígenas, de conhecerem, entenderem e dominarem a língua de seus antepassados. Somente desta forma se poderia permitir a conservação e uma revitalização cultural tão necessários a esses indivíduos.

O Estatuto do Índio Lei n. ${ }^{\circ}$ 6.001/73 prioriza o uso da Língua Materna como uso de educação indígena, evidenciando ainda mais a necessidade de que sejam criados Cursos de Formação Superior para esta demanda social de alunos indígenas (BRASIL, 1973). Assim, somando diferentes contextos e oportunidades, é que este estudo assume essa proposta de considerar a disponibilidade de um Curso de Formação Superior de Língua Indígena a ser disponibilizado pela UFRR.

Diferentes povos devem ter seus interesses representados, personificando essas necessidades em uma atitude ampla das instituições de formação superior. Santos (2011) afirma que as universidades, no atual momento, devem viabilizar o protagonismo de seus participantes em formação sendo que, não estando estes presentes ou representados dentro de seus mais diferentes setores formativos, está não deve estar inerte ao clamor de suas vozes. Muito pelo contrário, deve concreti- 
zar recursos, ferramentas e instrumentos que personifiquem seus anseios e necessidades. Somente desta forma se criariam universidades autônomas e representativas.

Santos (2004) avalia que as instituições de formação superior devem descentralizar o conhecimento, viabilizando encontros de formação no sentido de não privilegiar apenas alguns grupos, ou hegemonizar seus acessos de modo a tornar esquecidas minorias também detentoras dos mesmos direitos. A vivência acadêmica e sua rede integrada de ações e políticas de acesso devem ampliar horizontes para a criação não só de diferentes conhecimentos e saberes, mas seu leque a representações e respostas para ampla formação profissional. Isso se adequa àquilo que está diretamente compreendido como política integral de formação acadêmica.

Alvim (1995) descreve que essa abertura democrática às demandas presentes nas diferentes realidades sociais daqueles que necessitam de formação acadêmica é o que torna efetiva as políticas públicas de acesso ao ambiente acadêmico de modo a compor, nos diferentes setores profissionais, indivíduos que realmente são detentores de suas autonomias cidadãs e participativas. Isto é o que tornaria de modo mais evidente o papel do espaço integrado da realidade de uma formação superior.

Somente por meio dessas atitudes institucionais e pedagógicas, de acordo com o que afirma Soriano Ayala (2001) se poderá assumir uma luta mais ampla contra a segregação, o isolamento e a deterioração da identidade cultural presente nos pluralismos culturais, tal qual o presente nos povos indígenas de Roraima.

Pensar no acesso à cultura e a língua indígena é um fator primordial no Estado de Roraima e, adentrar nessas questões sinaliza um olhar para o patrimônio histórico-cultural do Estado que, em seus diferentes cenários desenvolveu e vem desenvolvendo alternativas importantes para a cultura local.

Os questionários aplicados até o momento no Insikiran/UFRR potencializarão esta pesquisa, buscamos neste momento trazer alguns direcionamentos que serão analisados no desenvolvimento da pesquisa.

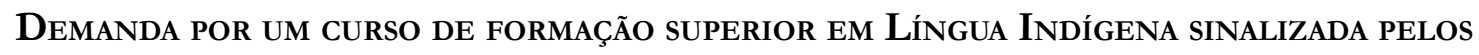 ALUNOS DO INSIKIRAN/UFRR}

Até o momento foram aplicados 21 questionários a 20 alunos da turma de Gestão em Saúde Coletiva 2019.1 do Insikiran/UFRR. Eles assinaram o Termo de Consentimento Livre e Esclarecido (TCLE). Nos questionários foram incluídas diversas questões, recortamos aqui o que interessa diretamente a discussão proposta neste texto. Adiante, compreenderemos um pouco melhor essas informações: foi indicado por 01 dos entrevistados o motivo gerador de uma demanda de alunos indígenas por um Curso de formação de professores de língua indígena a questão de haver seletivos que contratam professores biblíngues.

Um dos alunos Almeida (2019) disse que: "na maioria das vezes é inviável para o aluno indígena, sair de sua região" disse ainda que são motivos que impedem o aluno de vir a capital obter uma formação superior "[...] transporte e as condições das estradas em tempos de chuva". Esta fala revela como os alunos mesmo enfrentando uma série de dificuldades se esforçam para estudar. 
Gráfico 1. A importância, para os alunos, da disponibilidade de um Curso de Formação Superior em pelo menos uma das línguas indígenas de Roraima a ser ofertado pela UFRR)

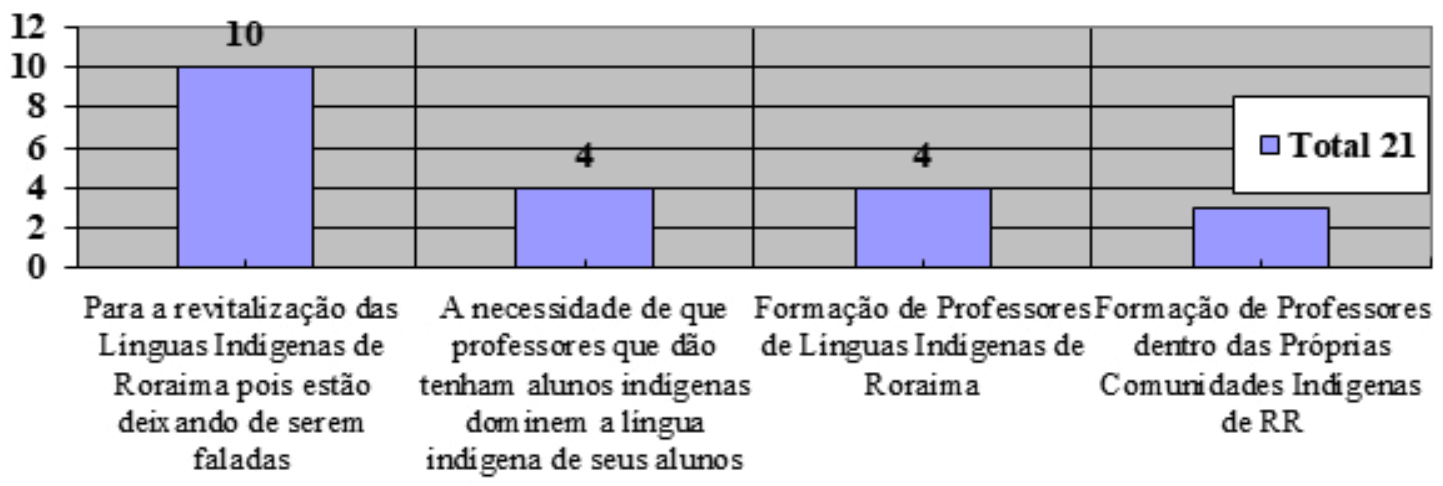

Fonte: Elaboração do Autor (2019).

$\mathrm{Na}$ Questão acima os alunos deveriam citar um motivo pelo qual seria importante para os alunos indígenas e não indígenas da UFRR, a disponibilidade de um Curso de Formação Superior em pelo menos uma das Línguas Indígenas de Roraima. Se não houver um motivo, descreva porque não seria importante. Entre as 21 respostas à questão, foram obtidas quatro perspectivas de respostas:

1) Para a revitalização das Línguas Indígenas de Roraima, pois estão deixando de serem faladas - indicado por 10 dos entrevistados como sendo um motivo pelo qual seria importante para os alunos da UFRR, a disponibilidade de um curso de Formação Superior em Língua Indígena. Este quantitativo representa $47,61 \%$ dos que responderam ao questionamento acima.

2) A necessidade de que professores que dão aula nas escolas indígenas tenham alunos indígenas dominem a língua indígena de seus alunos - indicado por 04 dos entrevistados como sendo um motivo pelo qual seria importante para os alunos da UFRR, a disponibilidade de um curso de Formação Superior em Língua Indígena. Este quantitativo representa 19,04\% dos que responderam ao questionamento acima.

3) Formação de Professores de Línguas Indígenas de Roraima - indicado por 04 dos entrevistados como sendo um motivo pelo qual seria importante para os alunos da UFRR, a disponibilidade de um curso de Formação Superior em Língua Indígena. Este quantitativo representa $19,04 \%$ dos que responderam ao questionamento acima.

Bernardi (2011) define que no atual momento histórico é necessária a formação de professores indígenas, visando a continuidade de suas culturas e reafirmação da construção dos elementos que as lideranças indígenas considerem importantes. Permitir esse protagonismo e garantir um tratamento equitativo no exercício da cidadania desses indivíduos.

Scriptori (2004) esclarece que cada vez mais as universidades contemporâneas devem identificar possibilidade e contextos que construam sociedades do conhecimento. Isto envolve alto grau de capacitação formativa e um melhor gerenciamento de políticas administrativas que somam esforços para acompanhar o desenvolvimento tecnológico da realidade atual.

\section{CONSIDERAÇÕES FINAIS}

A Universidade Federal de Roraima tem tido um trabalho pioneiro no que diz respeito ao elevado padrão de formação de profissionais para atuação no Brasil ou em outras localidades. Roraima trata-se de um estado com uma proporção considerável de indígenas que possuem como elemento 
de sua identidade multicultural suas línguas. Entre as perspectivas as quais a política administrativa e acadêmica da UFRR se fundamenta, podemos citar a Identidade, Multiculturalismo, Hibridismo Cultural e Interculturalismo. Assumindo esse posicionamento, já existe a oferta de cursos como Língua Portuguesa, Língua Francesa, Língua Inglesa e Língua Espanhola. Entretanto, não há, mesmo sob o contexto de uma grande quantidade de etnias indígenas, nenhum curso dentre as línguas indígenas de Roraima. Soma-se a esta constatação o fato de que são pouquíssimos estudos que tecem comentários e observações sobre esse contexto e panorama.

Fica evidenciado nesse momento, no que diz respeito a esta abordagem e estudo, que há um interesse por um curso de Formação Superior em Língua Indígena conforme o dito pelos alunos do Instituto Insikiran/UFRR. Ainda deve ser considerado que isso se trata de uma questão de autonomia de direitos desses alunos e, não só deles, mas de todos aqueles que identificam nessas culturas originárias da região Norte, algo a ser considerado e identificado como um elemento de diversidade cultural.

Esta abordagem de pesquisa e os elementos teóricos destacados nessa perspectiva de análise permitem descrever esses elementos. As falas dos alunos identificam dificuldades que poderiam ser superadas por meio de uma Formação Superior Indígena em uma das Línguas Indígenas de Roraima. A medida que trazemos ao conhecimento essas questões, possibilitamos uma melhor reflexão sobre esse assunto, percebemos, um dos autores como indígena do povo Macuxi, que a pesquisa científica pode dar voz e vez para esses indivíduos que por vezes, passam esquecidos das políticas acadêmicas que ficam, em muitos casos, limitadas a apenas alguns grupos.

\section{REFERÊNCIAS}

ALVIM, G. Autonomia Universitária e Confessionalidade. $2^{\mathrm{a}}$ edição. Piracicaba-SP: Unimep, 1995. BRASIL. Lei $\mathbf{N}^{\circ}$ 6.001, de 19 de dezembro de 1973. Estatuto do Î́ndio. Disponível em: <http://www. planalto.gov.br/ccivil_03/leis/16001.htm>. Acesso em: 31 de dez. de 2018.

, Lei de Diretrizes e Bases da Educação Nacional. Lei número 9394, 20 de dezembro de 1996. MEC, 1998.

Ministério da Educação. Referencial Curricular Nacional para as Escolas Indígenas. Brasília:

Parecer 14/99 do Conselho Nacional de Educação. Conselho Nacional de Educação - Câmara de Educação Básica. Diretrizes Curriculares Nacionais da Educação Escolar Indígena. Brasília - DF, 1999. , Instituto Brasileiro de Geografia e Estatística - IBGE. Características gerais dos indígenas no Censo Demográfico 2010 - resultados do Universo. Rio de Janeiro, 2012.

BOBBIO, N. A Era dos Direitos. Tradução: Carlos Nelson Coutinho. Editora Campus. Rio de Janeiro, 1992.

BANIWA, G. J. S. L. Entrevista concedida a Trilhas de Conhecimentos. Brasília, 2008. Disponível em $<$ http://www.trilhasdeconhecimentos.etc.br/mato_grosso_do_sul/index.html. Acesso em: 14 de set. de 2018 .

, Territórios etnoeducacionais: um novo paradigma na política educacional brasileira. In: CONAE, 2010, Brasília. Anais. Brasília, DF: MEC, 2010.

, Indígenas no Ensino Superior: Novo Desafio para as Organizações Indígenas e Indigenistas no Brasil. In: CONGRESSO INTERNACIONAL DE AMERICANISTAS, 53., 2009, México. Anais... México, 2009.

BAPTAGLIN, L. A. Aprendizagem na Docência: um olhar ara os cursos técnicos de ensino médio integrado. Apris, $1^{a}$ Ed. Curitiba: 2017, 239 p.

BERNARDI, L. T. M. dos Santos. Formação continuada em matemática do professor indígena Kaingang: enfrentamentos na busca de um projeto educativo. Tese (Doutorado) - Universidade Federal de Santa Catarina, 2011. Disponível em: <https://repositorio.ufsc.br/handle/123456789/95735>. Acesso em: 01 de mai. de 2019.

BRAGGIO, S. L. B. Políticas e direitos linguísticos dos povos indígenas brasileiros. (Projeto Contato 
entre línguas: Línguas indígenas brasileiras em contato com o português). Pós-Doutorado, University of New Mexico, 2001.

CANCLINI, N. G. Diferentes, desiguales y desconectados: mapas de la interculturalidad. Buenos Aires: Gedisa, 2004.

COHEN, G. V.; FOnSECA, T.; CARVAlHO, C. A. M. (Orgs). Gestão e Pesquisa: caminho e aprendizagem. Ed. UFRR, Boa Vista, 2016, 289 p.

FERNANDES, M. L.; CARVALHO, F., REPETTO, M. Acesso e permanência de indígenas ao ensino superior: O Programa E'ma Pia, UFRR. Boa Vista: Editora da UFRR, 2009.

FERNANDES, M. L. Indígenas no ensino superior: vagas específicas na UFRR. In: REPETTO, M.; FERNANDES, M. L.; NEVES, L. (Org.). Universidade inconclusa: os desafios da desigualdade. Boa Vista: Editora UFRR, 2008.

FRANK, E.H.; CIRINO, A. C. Desteritorialização e Re-territorialização dos Povos Indígenas de Roraima: Uma Revisão Crítica. In: BARBOSA, I. R.MELO F. V. (Org.). Roraima: Homem, Ambiente e Ecologia. Boa Vista: FEMACT, 2010.p.11 - 31.

MAHER, T., M. Do casulo ao movimento: a suspensão das certezas na educação bilíngüe e intercultural. In: CAVALCANTI, M.; BORTONI-RICARDO, S. M. (Orgs.). Transculturalidade, linguagem e educação. Campinas, SP: Mercado de Letras, 2007. p. 67-94.

OLIVEIRA, G. M. O que quer a linguística e o que se quer da linguística: a delicada questão da assessoria linguística no movimento indígena. Caderno Cedes, Campinas, v. 19, n. 49, p. 26-38, 1999. DOI: https:// doi.org/10.1590/S0101- 32621999000200004

PALADINO, M. (compiladoras) Educación escolar indígena: investigaciones antropológicas en Brasil y Argentina. Buenos Aires: Antropofagia: 2012, pp. 279-295.

ROMANOWSKI, J. P.; ENS, R. T. As pesquisas denominadas do tipo "estado da arte" em educação. Diálogo Educ., Curitiba, v. 6, n.19, 2006, p.37-50. Disponível em: <http://www.redalyc.org/ html/1891/189116275004/>. Acesso em: 01 de out. de 2018.

SANTOS, Boaventura de Sousa (Org.). Conhecimento prudente para uma vida decente. Um discurso sobre as ciências revisitado. São Paulo: Cortez, 2004.

A Universidade no século XXI: para uma reforma democrática e emancipatória da universidade. Cortez, $3^{a}$ Ed. São Paulo, 2011, 118 p.

SANTOS, S. C. Educação e sociedades tribais. Porto Alegre: Movimento, 1975.

SCRIPTORI, C. C. (org.) Universidade e Conhecimento: desafios e perspectivas no âmbito da docência, pesquisa e gestão. Campinas, SP: Mercado das Letras, 2004. p. 49 - 63. (Coleção Educação e Psicologia em Debate).

SORIANO AYALA, E. (coord) Identidad cultural y ciudadanía intercultural: su contexto educativo. Editorial La Muralla, S.A. $1^{\mathrm{a}}$ ed., $1^{\mathrm{a}}$ imp. Madrid, 2001. 